\title{
Synthesis and preliminary characterization of polyurethane nanoparticles with ginger extract as a possible cardiovascular protector
}

This article was published in the following Dove Press journal: International Journal of Nanomedicine

\author{
Florin Borcan' \\ Adela Chirita-Emandi ${ }^{2,3}$ \\ Nicoleta loana Andreescu ${ }^{2,3}$ \\ Livia-Cristina Borcan ${ }^{4}$ \\ Ramona Carmen Albulescu ${ }^{5}$ \\ Maria Puiu ${ }^{2,3}$ \\ Mirela Cleopatra Tomescu ${ }^{4}$ \\ 'The Ist Department (Analytical \\ Chemistry), Faculty of Pharmacy, "Victor \\ Babes" University of Medicine and \\ Pharmacy, Timisoara, Romania; ${ }^{2}$ The 2nd \\ Department (Genetics), Faculty of \\ Medicine, "Victor Babes" University of \\ Medicine and Pharmacy, Timisoara, \\ Romania; ${ }^{3}$ Center of Genomic Medicine, \\ "Victor Babes" University of Medicine \\ and Pharmacy, Timisoara, Romania; ${ }^{4}$ The \\ 5th Department (Internal Medicine I), \\ Faculty of Medicine, "Victor Babes" \\ University of Medicine and Pharmacy, \\ Timisoara, Romania; ${ }^{5}$ The IIth \\ Department (Pediatrics), Faculty of \\ Medicine, "Victor Babes" University of \\ Medicine and Pharmacy, Timisoara, \\ Romania
}

Background and aim: The extract of ginger, obtained from the rhizome of Zingiber officinale, contains 6-gingerol, 6-shogaol, 8-gingerol, and 10-gingerol. It has many therapeutic effects such as being chemopreventive against stroke and heart diseases, malabsorption, bacterial infections, indigestion, and nausea, which have been observed since ancient times. The main aim of this study is to evaluate the polyurethane (PU) as a proper material for the hollow nanoparticles' preparation.

Methods: The PU nanoparticles were obtained by a spontaneous emulsification, in the presence of a nonionic surfactant, combined with an interfacial polyaddition process between an aliphatic diisocyanate and different mixtures of etheric and esteric polyols. The synthesis was done without any PU additives, such as catalysts, blowing agents, chains promoters, cross-linking agents, and stabilizers.

Results: The particles present almost neutral $\mathrm{pH}$ values and low water solubility. They are heat resistant up to $280^{\circ} \mathrm{C}$. Decreased irritation level was found in the assay of PU nanoparticles loaded with pure ginger extract (GE) on the murine skin tests than the irritation level recorded for pure GE.

Conclusion: This research shows the reduced noxiousness of these PU nanoparticles and consequently the possibility of their use as a possible cardiovascular protector.

Keywords: $\mathrm{CD} 1 \mathrm{Nu} / \mathrm{Nu}$ mice, drug carrier, hollow nanoparticles, noxiousness, Zeta potential

\section{Introduction}

Cardiovascular diseases are disorders of heart and blood vessels including coronary artery disease, cerebrovascular disease, or peripheral arterial disease. ${ }^{1}$ Cardiovascular diseases are the leading cause of mortality in the world. Elevated levels of cholesterol and triglycerides, increased percentage of fat, and decreased percentage of muscle mass which are not counterbalanced by an efficient metabolism and a regular physical activity are favorable factors for cardiovascular diseases. ${ }^{2}$

Phytotherapy is a therapeutic method which uses medicinal plants to ameliorate disease. This kind of therapy is a thousand years old and has already proven its efficiency. Unlike allopathic medicine, which recommends only substances extracted from plants, phytotherapy uses plants as total extracts. Various parts of the plant are used - together or separately, as appropriate - from roots to flowers, including bark and buds. ${ }^{3}$ The following main categories of phytocompounds are used in different therapies: flavonoids (rutin, quercetin, epicatechin, kaempferol, etc.), phenolic acids
Correspondence: Livia-Cristina Borcan The 5th Department (Internal Medicine I), Faculty of Medicine, "Victor Babes"

University of Medicine and Pharmacy, 2nd

E. Murgu Sq., Timisoara 30004I, Romania

Tel +40745329795

Fax +40356780037

Email borcan.cristina@umft.ro 
(capsaicin, rosmarinic acid, and tannic acid), hydroxycinnamic acid (coumarin and ferulic acid), organosulfides (allicin, glutathione, and sulforaphane), alkaloids (theophylline and caffeine), carotenoids (beta-carotene and lycopene), anthocyanins, terpenes, isoflavones, and phytosterols. ${ }^{4}$ Vasanthi et al described that a part of isoflavones, diosgenin, resveratrol, quercetin, catechin, sulforaphane, tocotrienols, and carotenoids were already found to reduce the risk of cardiovascular diseases and aid in cardioprotection by their antioxidative, antihypercholesteroemic, antiangiogenic, antiischemic, inhibition of platelet aggregation, and antiinflammatory activities. ${ }^{5}$

Polyurethane (PU) materials appear for the first time 80 years ago in I.G. Farbenindustrie Laboratories from Leverkusen; Prof. O. Bayer obtained PU foams from toluene diisocyanate and polyester polyols. ${ }^{6}$ The use of PU in the field of drug delivery is relatively recent: Hong and Park developed the first PU microcarrier two decades ago. ${ }^{7} \mathrm{We}$ already obtained PU nano- and microstructures with different shapes and sizes in the last 5 years. $^{8-12}$ The aim of this study is to obtain and to characterize a mixture of polyesterand polyether-urethanes which can assure a constant release of apure ginger extract (GE) for a prolonged time.

\section{Material and methods}

\section{Reagents}

The characteristics of the main commercial reagents are presented in Table 1. Reagents were kept under the conditions indicated by the manufacturer, and they were used without further purifications.

\section{Obtaining of GE}

Munteanu et al described the procedure which was chosen for obtaining the GE; ${ }^{10}$ the ginger root was crushed using a chisel, and it was rapidly dried at $90^{\circ} \mathrm{C}$ for 2 days and extracted with $70 \%$ ethanol for $24 \mathrm{hrs}$. The obtained mixture was then filtered, centrifuged at $25^{\circ} \mathrm{C}$ with $2,000 \mathrm{rpm}$ for $5 \mathrm{mins}$, and concentrated using a rotavapor at $90^{\circ} \mathrm{C}$ until constant weight.

\section{Synthesis of nanoparticles}

The procedure chosen for the synthesis is based on an interfacial polyaddition reaction (Figure 1) combined with a spontaneous emulsification; the protocol presents the following steps: ${ }^{11,12}$

1. Preparation of the aqueous phase (PU soft segment) a mixture of BD, PEG and PCL, Tween ${ }^{\circledR} 20$, and distilled water $0.5: 1: 1: 30$ was heated at $35^{\circ} \mathrm{C}$ and homogenized in an Erlenmeyer flask $(100 \mathrm{~mL})$;

2. Preparation of the organic phase (PU hard segment) - a mixture of LDI and acetone 1:15 was heated at $35^{\circ} \mathrm{C}$ and homogenized in a Berzelius beaker $(50 \mathrm{~mL})$;

3. The organic component was injected into the aqueous one under magnetic stirring $(400 \mathrm{rpm})$ and heated $\left(35^{\circ} \mathrm{C}\right)$. The PU nanoparticles start to appear in this

Table I The main characteristics of the reagents

\begin{tabular}{|c|c|c|c|c|c|}
\hline $\begin{array}{l}\text { Chemical name, } \\
\text { abbreviation }\end{array}$ & CAS no. & Aspect & $\begin{array}{l}\text { Molar mass }(\mathrm{g} / \mathrm{mol}) \\
\text { and density }\left(\mathrm{g} / \mathrm{cm}^{3}\right)\end{array}$ & $\begin{array}{l}\text { Melting/boiling } \\
\text { point, }{ }^{\circ} \mathrm{C}\end{array}$ & Manufacturer \\
\hline I,4-butanediol, & $110-63-4$ & Colorless viscous & 90.12 & 16 & Carl Roth GmbH \\
\hline I,4-BD & & liquid & 1.017 & 230 & (Germany) \\
\hline Lysine-diisocyanate, & $45172-15-4$ & Yellow viscous liquid & 226.23 & -305 & Hangzhou ImagineChem \\
\hline LDI & & & 1.128 & & Co. Ltd (China) \\
\hline Polyethylene glycol, & $25322-68-3$ & Colorless viscous & $190-210$ & -50 & Merck (Germany) \\
\hline PEG & & liquid & 1.124 & $>150$ & \\
\hline Polycaprolactone diol, & $36890-68-3$ & Paste & $\sim 530$ & $36-48-$ & Merck (Germany) \\
\hline PCL & & & 1.073 & & \\
\hline \multirow[t]{2}{*}{ Tween ${ }^{\oplus} 20$} & \multirow[t]{2}{*}{$9005-64-5$} & Yellowish viscous & $\sim 1,228$ & \multirow[t]{2}{*}{$\geq 100$} & \multirow[t]{2}{*}{ Merck (Germany) } \\
\hline & & liquid & 1.095 & & \\
\hline Dimethyl-sulfoxide, & $67-68-5$ & Colorless liquid & 78.13 & 16 & Fluka (Germany) \\
\hline DMSO & & & 1.10 & 189 & \\
\hline \multirow[t]{2}{*}{ Acetone } & \multirow[t]{2}{*}{$67-64-1$} & \multirow[t]{2}{*}{ Colorless liquid } & 58.08 & -95 & \multirow[t]{2}{*}{ Chimopar SA (Romania) } \\
\hline & & & 0.791 & 56 & \\
\hline \multirow[t]{2}{*}{ Ethanol } & \multirow[t]{2}{*}{$64-17-5$} & \multirow[t]{2}{*}{ Colorless liquid } & 46.07 & -114 & \multirow[t]{2}{*}{ Chimopar SA (Romania) } \\
\hline & & & 0.789 & 78 & \\
\hline
\end{tabular}

Note: Information was collected from the providers' papers. 


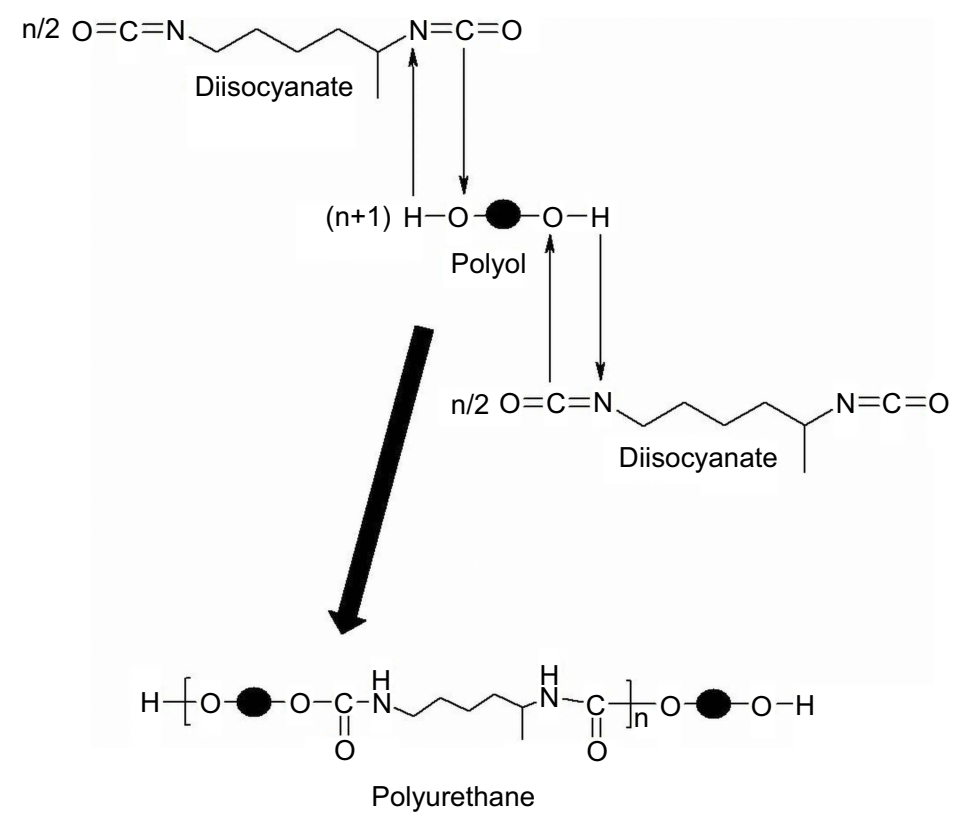

Figure I The chemical reaction used for the synthesis of polyurethane particles.

moment as a white precipitate. However, the stirring is maintained for $3 \mathrm{hrs}$ at $40^{\circ} \mathrm{C}$ in order to ensure the completion of all chemical reactions (maturation time);

4. The obtained suspensions were repeatedly washed with a mixture (acetone-water $3: 1 \mathrm{v} / \mathrm{v}$ ) in order to eliminate unwanted/secondary products such as amines;

5. The solvent and a part of water were removed by slow evaporation, keeping the suspension as thin layers at $50^{\circ} \mathrm{C}$ for around $72 \mathrm{hrs}$.

The procedure previ ously described was repeated six times using different PEG/PCL ratios and with/without GE. Table 2 presents the main raw materials used for the two sample: sample PU_0 is a mixture 1:1:1 (w/w) of the first three syntheses' products, while PU_1 combines the last three syntheses' products at the same ratio, because the combining of samples with different polyether/polyester ratios leads to products containing particles with different degradation speed and assures an approximately constant concentration of drug released.

\section{$\mathrm{pH}$ and solubility measurements}

The preliminary characterization of PU nanoparticles with and without GE starts by a series of dissolution tests. Distilled water, ethanol, acetone, and DMSO were used as solvents, following a procedure described in ASTM D $3132-84 .^{13}$

The $\mathrm{pH}$ of $\mathrm{PU}$ nanoparticles samples was evaluated using a portable $\mathrm{pH}$ Meter Checker ${ }^{\circledR}$ (Hanna Instruments, Woonsocket, RI, USA) and aqueous solutions with the

Table 2 The raw materials for PU nanoparticle synthesis

\begin{tabular}{|l|l|l|l|l|l|}
\hline \multirow{2}{*}{ Sample code } & \multicolumn{2}{|l|}{ Aqueous phase } & Organic phase & \multirow{2}{*}{ Ginger extract, mL } \\
\cline { 2 - 6 } & BD, $\mathbf{~ m L}$ & PEG/PCL, $\mathbf{~ m L}$ & Tween 20, $\mathbf{~ m L}$ & LDI, $\mathbf{~ m L}$ & \\
\hline PU_0 & 0.6 & $0.2+1.0$ & 1.2 & 2.0 & - \\
& & $0.6+0.6$ & & & 1.8 \\
PU_I & $1.0+0.2$ & 1.2 & 2.0 & \\
& 0.6 & $0.2+1.0$ & & & \\
\end{tabular}

Abbreviations: PU, polyurethane; BD, I,4-butanediol; PEG, polyethylene glycol; PCL, polycaprolactone diol; LDI, lysine diisocyanate; PU_0, polyurethane sample without ginger extract; PU_I, polyurethane sample with ginger extract. 
same concentration $(0.8 \mathrm{mg} / \mathrm{mL})$ at the same temperature $\left(25^{\circ} \mathrm{C}\right)$. The instrument was previously calibrated using four different buffer solutions $(\mathrm{pH}=3,5,7$, and 10).

\section{Matrix-assisted laser desorption ionization time-of-flight mass spectrometry (MALDI-TOF MS) analysis}

The MALDI-TOF technique was used to determine any change in the nanoparticle chemistry following the addition of GE during the synthesis. Gingerol, as the main constituent of GE, is a chemical compound with two hydroxyl groups, and it can be a chain extender during the particle synthesis.

The Bruker HCCA (alpha-cyano-4-hydroxycinnamic acid) matrix $(5 \mathrm{mg} / \mathrm{mL}$ in a mixture of acetonitrile, water, and trifluoroacetic acid) was used to suspend the nanoparticles. $1 \mu \mathrm{L}$ suspension was added onto the target plate (MTP 384 ground steel, Bruker Daltonics, Bremen, Germany). The spots were allowed to dry at room temperature.

The mass spectra were obtained using UltrafleXtreme MALDI TOF/TOF instrument (Bruker Daltonics). The analysis was performed in positive ion reflectron mode in a mass range of $700-3,500 \mathrm{~m} / \mathrm{z}$. The instrument was calibrated using Bruker Peptide Calibration Standard I containing mixture of seven standard peptides. Flex Control ${ }^{\circledR}$ (version 3.4) software was used to acquire the data and set the method parameters. The following settings were used: laser frequency $-1,000 \mathrm{~Hz}$; smartbeam - "4_large"; sample rate and digitiser settings $2.50 \mathrm{GS} / \mathrm{s}$; accelerator voltage $-20.12 \mathrm{~kW}$; extraction voltage $17.89 \mathrm{~kW}$; lens voltage $-7.23 \mathrm{~kW}$; delayed extraction $-120 \mathrm{~ns}$; and reflector voltage $-20.23 \mathrm{~kW}$. The laser intensity was adjusted such that the highest peak in the spectrum was in the range of 104 arbitrary units. 1,000 laser shots were used for each individual spectrum and minimum 10 individual spectra (10,000 laser shots) were cumulated and saved.

The mass spectra were processed using Flex Analysis ${ }^{\circledR}$ software (version 3.4, Bruker Daltonics).

\section{Yield of encapsulation}

Bouchemal et al described a procedure to evaluate the amount of an active agent entrapped inside PU nanocapsules; the protocol is based on the determination of free/ untrapped drug using its UV-Vis absorption related to the quantity of this drug added into synthesis. ${ }^{14}$

The formula is: Yield of encapsulation $=(1-$ Quantity of free drug/Quantity of drug added) $\dot{\times} 100$.

\section{Thermal analysis}

The thermal behavior of samples containing PU nanoparticles was studied by differential scanning calorimetry (DSC). Small amounts of samples, between 3.4 and $3.7 \mathrm{mg}$, were placed inside aluminum crucibles with pierced caps, and they were heated between $30^{\circ} \mathrm{C}$ and $280^{\circ} \mathrm{C}$ in an inert atmosphere (a flow rate of $100 \mathrm{~mL} / \mathrm{min}$ Ar was used to prevent sample contamination and oxidation during the DSC runs) with a heating speed equal with 5 degree/min. A reference material (empty aluminum crucible with pierced cap) simultaneously undergoes the same routine. The instrument, a DSC1 (Mettler-Toledo, Greifensee, Switzerland), was previously calibrated with the use of $\mathrm{Zn}$ and In as standards.

\section{Zetasizer measurements}

The size and the surface charge of the PU nanoparticles with and without GE were evaluated using a Cordouan Zetasizer (Cordouan Technologies, Pessac, France). This instrument contains two different analyzers: a Vasco Particle Size Analyzer and a Wallis Zetapotential Analyzer. The following parameters were set in the case of Vasco Analyzer: working temperature $\left(25^{\circ} \mathrm{C}\right)$; time intervals $(22 \mu \mathrm{s})$; number of channels $(410 \pm 20)$; laser power $(80 \pm 5 \%)$; acquisition mode (continuous) and analysis mode (Pade-Laplace). In the case of Wallis Zetapotential Analyzer (Cordouan Technologies, Pessac, France), the parameters were: plastic cuvette with applicability between 380 and $780 \mathrm{~nm}$; temperature $\left(25^{\circ} \mathrm{C}\right)$; laser power $(75 \pm 5 \%)$; applied field (automatic); resolution ( $0.8 \mathrm{~Hz}$ - medium); 3 measures/sequence, and Henry function (Smoluchowski).

\section{Test of membrane penetration}

The penetrability of polymer nanoparticles with and without GE through membranes was tested using a PVDF (polyvinylidene fluoride) artificial membrane Spectra/Por ${ }^{\circledR}:{ }^{15}$ $2.0 \mathrm{~mL}$ sample was loaded inside a dialysis tube and $100 \mathrm{~mL}$ saline buffer were used in the external chamber. The experiment was done at room temperature and at every $10 \mathrm{hrs}, 1.0 \mathrm{~mL}$ liquid from the external chamber was replaced with fresh buffer, and it was analyzed by comparing the absorbance recorded on a UVi Line 9400 (SI Analytics, Mainz, Germany) at $290 \mathrm{~nm}$.

\section{In vivo evaluations}

Twelve $\mathrm{CD} 1 \mathrm{Nu} / \mathrm{Nu}$, 2-month-old, female mice were purchased from Charles River (Budapest, Hungary) and they were divided into four equal groups: group B (mice used 
as blank, treated with solvent), group PU_0 (mice treated with PU nanoparticles solution), group PU_1 (mice treated with solution of particles loaded with GE), and group $\mathrm{G}$ (mice treated with pure GE).

The solutions were applied on the back skin every third day ( $0.5 \mathrm{~mL} /$ application) and the determinations of skin parameters were performed within 20 mins after each application. All measurements were carried out according to the published guidelines ${ }^{16}$ with a Multiprobe Adapter System (MPA5) from Courage\&Khazaka Electronics, Germany, equipped with a Tewameter ${ }^{\circledR}$ TM300 probe and a Mexameter ${ }^{\circledR}$ MX18 probe, at the same moment of the day, by the same operator, in a narrow range of temperature $\left(22 \pm 1{ }^{\circ} \mathrm{C}\right)$ and air humidity $(40 \pm 3 \%)$.

Human and animal skin has a crucial role in the protection of the body against different pathogens. ${ }^{17}$ The Tewameter ${ }^{\circledR}$ TM300 probe is designed to evaluate the barrier role of skin. The transepidermal water loss (TWL) is a natural process whose important increases show a disruption of the skin barrier (wounds, scratches, burns, exposure to solvents or surfactants, and extreme dryness) and it was reported as a good parameter to predict the irritation potential of a given compound. $^{18}$

On the other hand, mexametry is a technique used to determine the two components of skin color: melanin and hemoglobin (erythema). ${ }^{19}$ The Mexameter ${ }^{\circledR}$ MX18 probe emits green, red, and infrared and the quantity of light absorbed by the skin is calculated in just 1-3 s.

\section{Statistics and ethical approval}

All statistical analyses were performed using a trial version of IBM SPSS. The measurements from this study were done in triplicate, and the results are expressed as mean \pm SE. One-way ANOVA and Bonferonni-Dunn tests were used to determine the statistical difference between experimental and blank groups; *, ** and *** indicate $p<0.05, p<0.01$, and $p<0.001$.

All investigations were done according to the declaration of Helsinki principles. Authors declare that all procedures involving animal subjects respect the specific regulations and standards: this study was first evaluated and approved by the Ethical Committee of "Victor Babes" University of Medicine and Pharmacy Timisoara, Romania. The work protocol followed the rules of the National Institute of Animal Health: during the experiment, animals were maintained in standard conditions of
$12 \mathrm{hr}$ light-dark cycle, food, and water ad libitum, at 25 $\pm 1^{\circ} \mathrm{C}$ and humidity $>55 \%$.

\section{Results}

\section{Evaluation of samples stability}

The stability of samples was first monitored after their syntheses in a similar manner to that described by Borcan et al: ${ }^{11}$ a part of every sample was separated after purification, and it was divided and maintained at 3 different temperatures $\left(8 \pm 0.1^{\circ} \mathrm{C}\right.$ in a refrigerator, $25 \pm 0.1$ and $40 \pm 0.1$ in a laboratory incubator) for 30 days. The aspect including the color of samples was stable all this period.

\section{$\mathrm{pH}$ and solubility measurements}

Table 3 presents the $\mathrm{pH}$ and solubility values of samples containing PU particles without and with GE (PU_0 and PU_1). Increased solubility values of PU sample with GE were observed in water, ethanol, and acetone, and this may be due to the fact that PU chains may have a different number of free hydroxyl groups depending on the entrapped drug.

\section{MALDI-TOF MS analysis}

The main component of our synthesis (PEG) can be observed on MALDI-TOF MS spectra (Figure 2). Both samples (PU_0 and PU_1) present similar spectra with an average $m / z$ of 1,420 . In both samples, the most intense peak was observed at $1,199 \mathrm{~m} / \mathrm{z}$. The adjacent peaks differ in mass by one monomer unit (average of $44.5 \mathrm{~m} / \mathrm{z}$ ). No significant differences were observed between the two samples, and therefore no change was detected in the particle chemistry, when loaded with the extract.

Ketata et al have described in their paper that PU fragmentation is similar to its thermal decomposition; the recast of the raw materials (polyol and diisocyanate) is the main pathway of these degradation processes. ${ }^{20}$

Table $3 \mathrm{pH}$ and solubility of samples in different solvents

\begin{tabular}{|l|l|l|}
\hline Parameter vs sample & PU_0 & PU_I \\
\hline $\mathrm{pH}$ & $6.09 \pm 0.19$ & $6.02 \pm 0.27$ \\
Solubility in water, $\mathrm{mg} / \mathrm{mL}$ & 0.83 & 0.87 \\
Solubility in ethanol, $\mathrm{mg} / \mathrm{mL}$ & 0.91 & 0.92 \\
Solubility in acetone, $\mathrm{mg} / \mathrm{mL}$ & 1.09 & 1.13 \\
Solubility in DMSO, $\mathrm{mg} / \mathrm{mL}$ & 1.05 & 1.05 \\
\hline
\end{tabular}

Abbreviations: DMSO, dimethyl-sulfoxide; PU, polyurethane; PU_0, polyurethane sample without ginger extract; PU_I, polyurethane sample with ginger extract. 

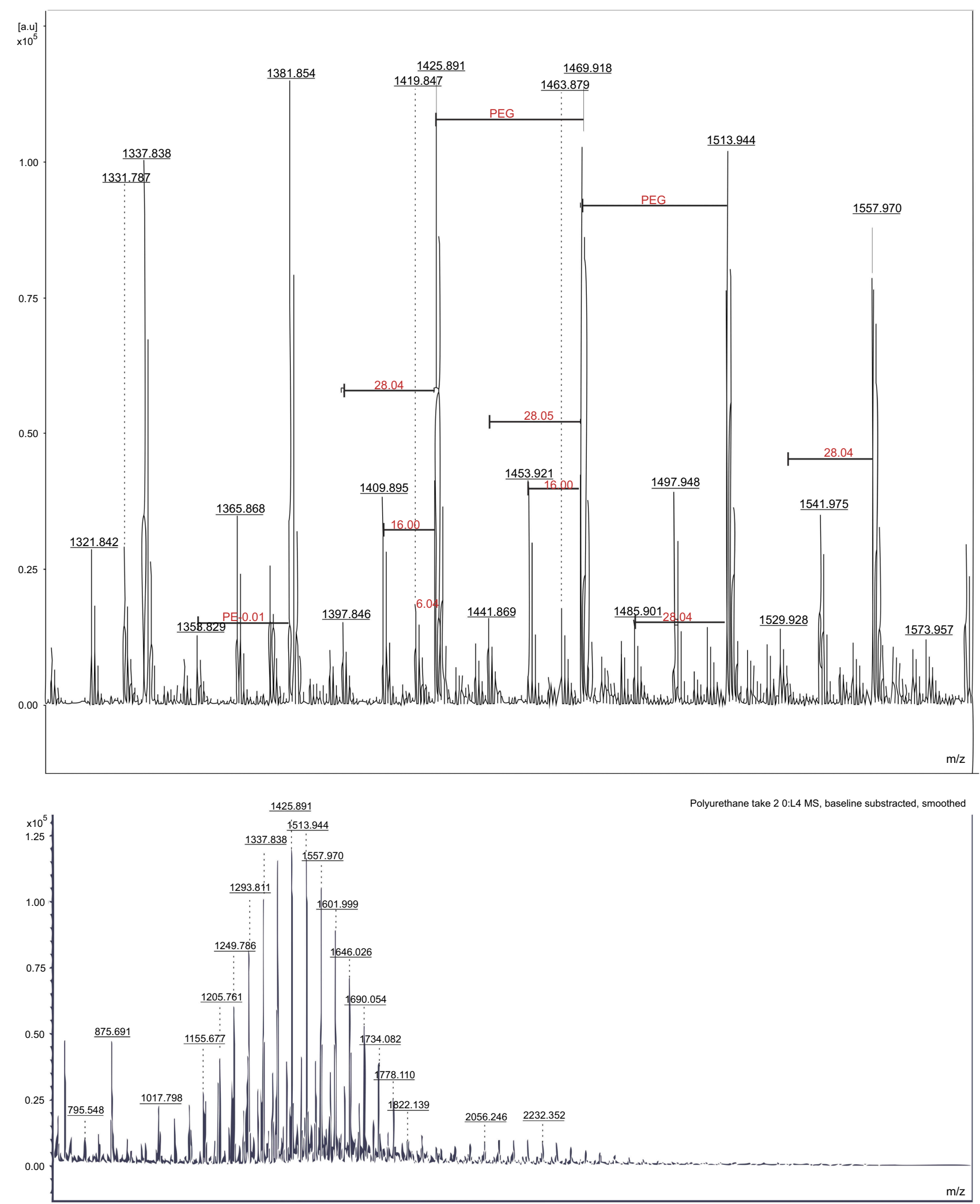

Figure 2 MALDI-TOF spectra of polyurethane particles.

Notes: $L 4$ represents the number of mass spectrometry analyses done on our polyurethane (PE) sample. PEG and PE represent polyethylene-glycol and PE fragments. Red color was used to highlight the fragments (28, mass of ethylene) whilst black numbers were used for the main $\mathrm{m} / \mathrm{z}$ peaks. The top image is a detailed spectra (a part of the bottom one - around $m / z=1420$ ).

Abbreviation: MALDI-TOF, matrix-assisted laser desorption ionization time-of-flight mass spectrometry. 


\section{Yield of encapsulation}

The maximum absorbance of PU samples is between 300 and $310 \mathrm{~nm}$, while GE presents a peak at $386 \mathrm{~nm}$ (Figure 3). This wavelength was chosen to evaluate the amount of free active substance; four solutions with different concentrations were prepared, and a graph absorbance vs calibration was drawn $\left(\mathrm{R}^{2}=0.997\right)$. An encapsulation efficiency equal with $82.9 \%$ was obtained by reporting the amount of free drug to the quantity of all GE added to synthesis.

\section{Thermal analysis}

DSC curves indicate the melting and boiling point of an unknown sample (endothermic phase transitions), a crystallization (an exothermic process), and other material parameters such as the vitreous transition of polymers, etc., ${ }^{21}$ The PU nanoparticles are stable within the studied temperature range. Bolcu et al have described that PU decomposition starts at around $300 \pm 20^{\circ} \mathrm{C}$ depending on the aliphatic/aromatic character of diisocyanate radicals. ${ }^{22}$ No important difference was observed between the sample with and without GE (Figure 4).

\section{Zetasizer measurements}

Table 4 presents the size and surface charge values of the PU nanoparticles without and with GE (PU_0 and PU_1).

Munteanu et al have presented that colloidal suspensions with zeta potential values $>30 \mathrm{mV}$ are exceptionally stable, while particles with zeta potential between 20 and $30 \mathrm{mV}$ have a medium tendency to form clusters in order to increase their stability. ${ }^{10}$ The particle sizes are $<100 \mathrm{~nm}$; thus, it can be appreciated that this carrier contains nanoparticles.

\section{Test of membrane penetration}

The nanoparticles play an important role in modern medicine due to their increased mobility, chemical reactivity, and energy absorption. Murthy wrote about quantum dots and their applications in optical images, superparamagnetic iron oxide nanoparticles in magnetic resonance imaging, and polymer- and liposome-based nanoparticles used in drug and gene delivery. ${ }^{23}$

Their increased mobility allows passing different membranes. However, the transmembrane transport is limited to their size, shape, and surface properties. The membrane penetration was evaluated using the dialysis procedure, and the variation of GE concentration was calculated by Beer-Lambert law at $386 \mathrm{~nm}$ (Figure 5).
The PU nanoparticle degradation starts with a delay of 2 days, and a maximum concentration of GE passed through an artificial membrane was obtained after 3-4 days. This situation is often met in the case of PEGylated particles used as drug carriers; polyetherbased particles present a delayed degradation due to their increased stability against hydrolysis.

\section{In vivo evaluations}

The skin is a sensitive organ that modifies its parameters during different experiments. The skin tissue is different from one person to another and it depends on the life experience, job, and daily personal care. Irritation agents such as strong acidic compounds or alkali change the important parameters of skin such as the transepidermal water loss, erythema, and the level of stratum corneum hydration. Figure 6 presents the evolution of TWL.

In skin evaluations, TWL has increased significantly in the case of pure GE during the 3-week experiment, and this increase can be associated with an irritation effect. The skin patches with hot peppers are well known to relieve the rheumatic pain, and, on the other hand, the irritation character of spicy herbs is known too. TWL evolution presents lower increases in the case of GE entrapped inside PU nanoparticles; thus, we can appreciate that this carrier is proper due to its lower irritation effect.

The skin pigmentation is mainly based on the level of melanin. People with Fitzpatrick Skin Phototype I always suffer skin burns and not tan, while those with Phototype $\mathrm{V}$ and VI always develop dark $\tan ^{24} \mathrm{CD} 1 \mathrm{Nu} / \mathrm{Nu}$ mice strain has a white and sensitive skin; this is the reason why small increases of melanin index were obtained during our experiment. The melanin scale used by Courage-Khazaka has 1,000 arbitrary units; thus, our changes (around 70 units/3 weeks) are insignificant (Figure 7).

Erythema, probably the most important skin parameter, was another skin parameter evaluated in our experiment. Figure 8 presents an important increase of hemoglobin level in the case of mice treated with GE. This increase confirms the skin alteration that was suggested by the increase of TWL. The other samples, the PU nanoparticles with and without GE, present similar increases with the blank.

\section{Discussion}

Nanotechnology is considered at this moment as an "emerging technology" that can revolutionize a large number of domains. In pharmaceutical technology, a research major priority is the development of alternative routes of drug 


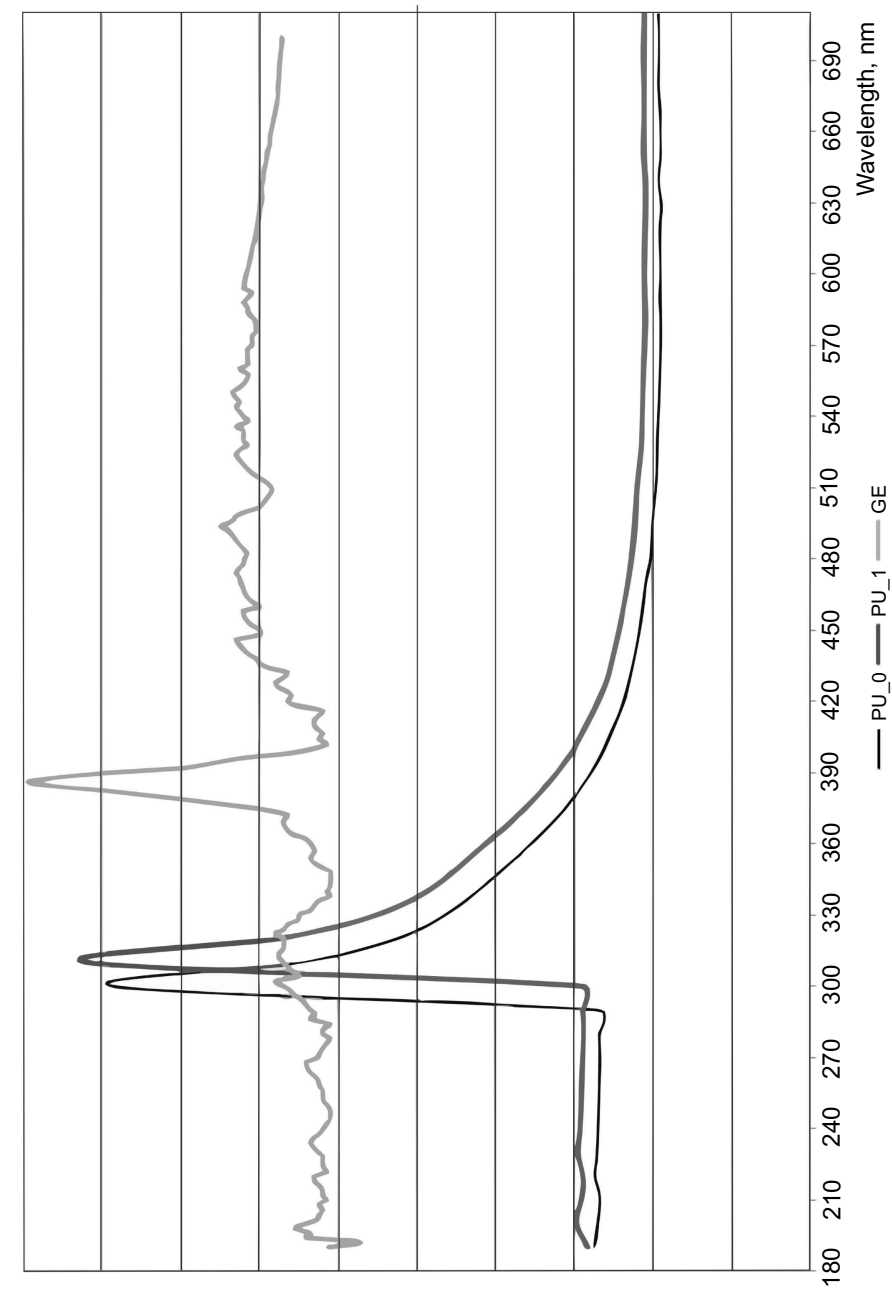

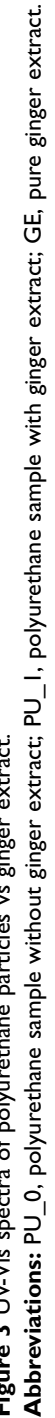




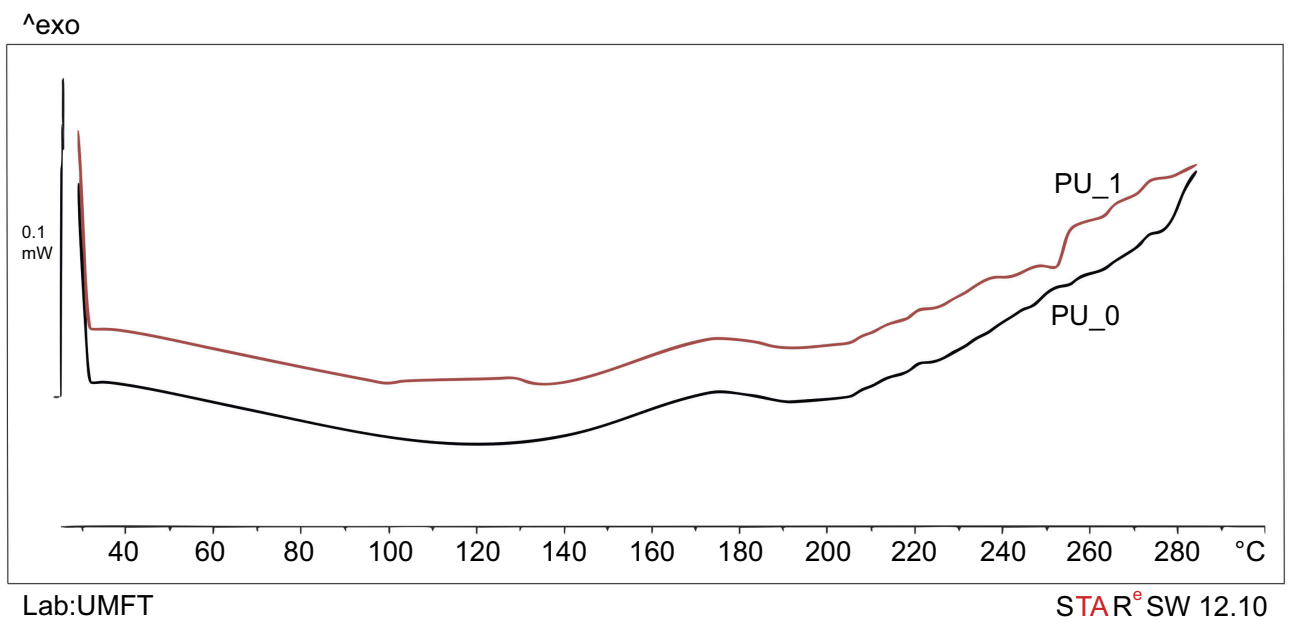

Figure 4 DSC thermograms of polyurethane samples.

Abbreviations: DSC, differential scanning calorimetry; PU, polyurethane; PU_0, polyurethane sample without ginger extract; PU_I, polyurethane sample with ginger extract; Lab, laboratory; UMFT, University of Medicine and Pharmacy Timisoara; exo, exoterm.

Table 4 Zetasizer characterization of synthesized samples

\begin{tabular}{|l|l|l|l|}
\hline Sample code & Average size, $\mathbf{n m}$ & PDI & Zeta potential, mV \\
\hline PU_0 & $88 \pm 12$ & 0.4 & $+25.7 \pm 3.5$ \\
PU_I & $90 \pm 9$ & 0.7 & $+27.8 \pm 4.1$ \\
\hline
\end{tabular}

Abbreviations: PDI, polydispersity index; PU, polyurethane; PU_0, polyurethane sample without ginger extract; PU_I, polyurethane sample with ginger extract.

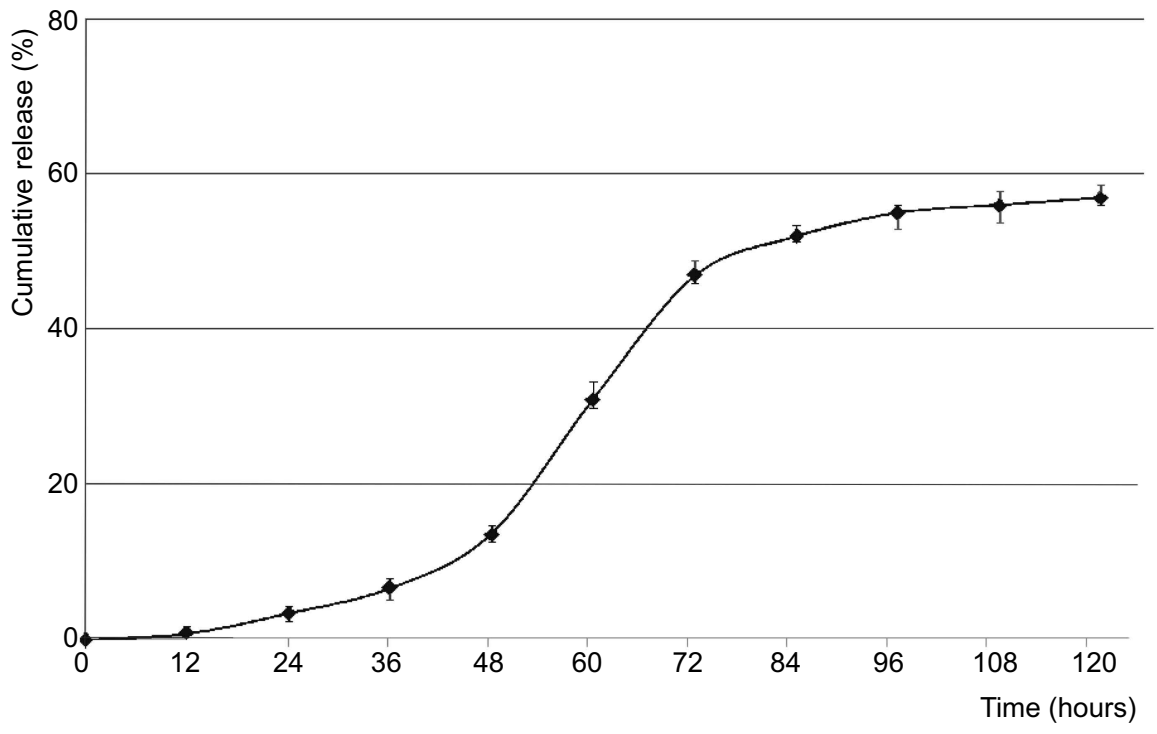

Figure 5 The evolution of ginger extract amount passed through a membrane.

administration. ${ }^{25}$ The appearance of nanomedicine and drug delivery systems, in particular, the polymeric carriers, is correlated with the advancement in understanding disease mechanisms and with the development of new polymer structures and synthetic methodologies for adapting its physicochemical properties. Although the drug delivery systems based on synthetic polymers have been used in drug delivery in recent decades, there are several examples of new macromolecules used in the field. It is important to explore these macromolecules and to persevere in the investigation of their production methods, cleaner, and more efficient and less costly although clinical approval 


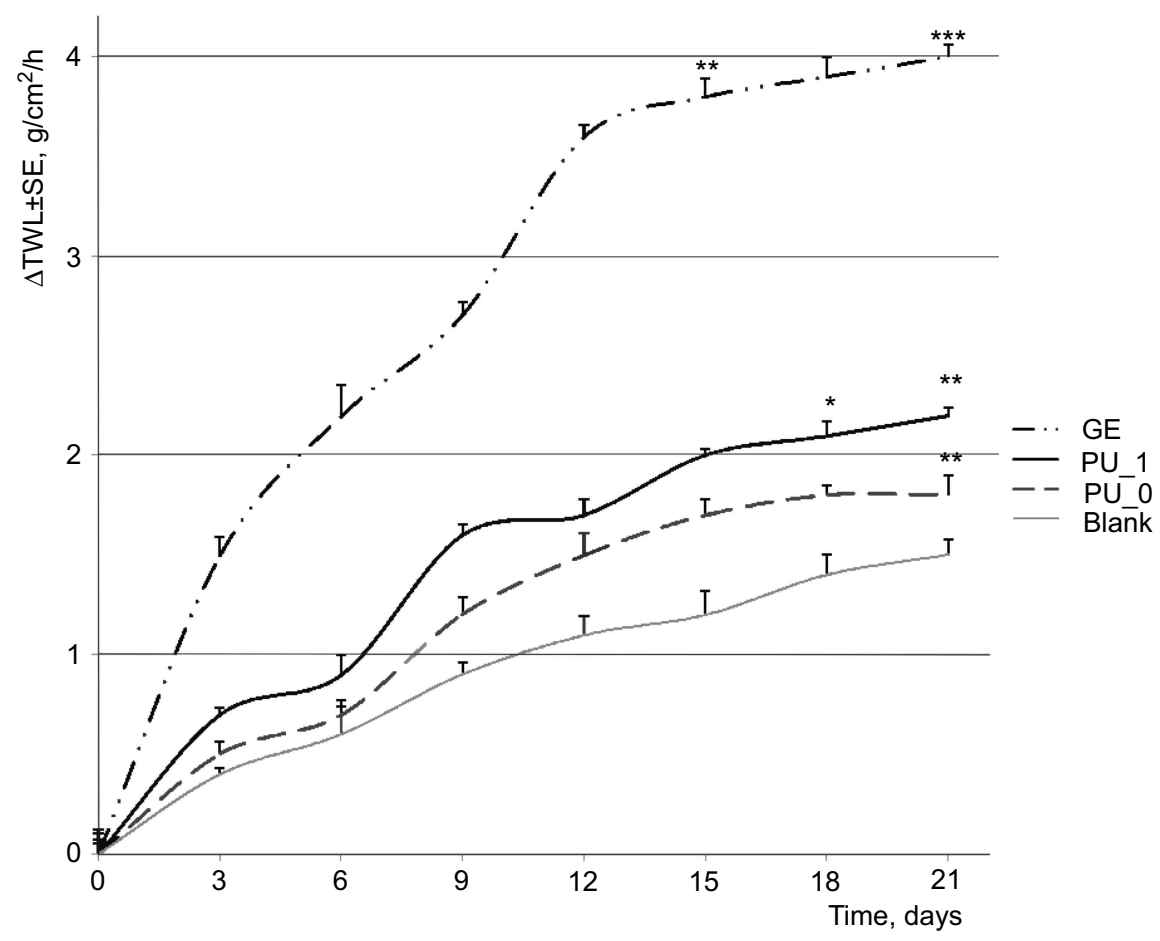

Figure 6 Evolution of TWL during the experiment.

Abbreviations: PU_0, polyurethane sample without ginger extract; PU_I, polyurethane sample with ginger extract; GE, pure ginger extract; TWL, transepidermal water loss.

of them may be strenuous. Nonetheless, clinical approval of them may be strenous. ${ }^{26}$

GE is often used due to its rich composition of volatile oils. In traditional Chinese, Indian, and Japanese medicine, it was used due to the heater effect, to increase digestive capacity, in bloating, nausea, vomiting, as well as in respiratory diseases characterized by the increase in cold quality. In Africa, the plant was introduced in the 15th century, being used by natives in cases of malaria and yellow fever. The first medical treatment based on ginger was written in the 13 th century by Dr. Rhiwallow at the order of the Prince of South Wales. Ginger is currently grown in tropical countries around the world. ${ }^{27,28}$

Verma et al described that dried ginger powder has an important protective effect on cardiovascular disease by decreasing the lipid peroxidation and enhancing the fibrinolytic activity on experimentally induced atherosclerosis in rabbits. ${ }^{29} \mathrm{~A}$ treatment with just $1 \mathrm{~g}$ ginger powder has a synergetic effect on nifedipine and on antiplatelet aggregation in hypertensive patients, and a dose of $10 \mathrm{~g}$ powder exhibits a significant reduction of platelet aggregation in patients with coronary artery disease. ${ }^{30,31}$ On the other hand, the scientific literature presents that natural compounds from ginger have beneficial effects on blood pressure and they can be beneficial in lowering elevated blood glucose levels and lipid concentrations. ${ }^{32-37}$

The ethanol extract suppresses the increase of body weight and decreases the levels of insulin and serum glucose induced by a fat diet. ${ }^{38}$ Unfortunately, this extract is contraindicated in gastritis and gastroduodenal ulcers due to the synergism effects of alcohol and its chemical compounds. The encapsulation of GE inside a drug delivery system with controlled release is a solution to this problem.

The molecular weight of polymers always presents a distribution with different dispersity. The polydispersity index (PDI) value is the ratio between the weight average molecular mass $(\mathrm{Mw})$ and the number average molecular mass (Mn). ${ }^{39} \mathrm{Mn}$ depends on the mass of PEG used as raw material and the dependence is almost linear; Ketata et al found by ESI/MALDI-TOF technique that Mn of a PU synthesized by PEG 200 is 230, while the Mn of a PU based on PEG 2000 is 2,030. ${ }^{40}$ Different PU nanoparticles have been obtained in this study in order to assure a prolonged release of GE; PDI between 0.4 and 0.7 indicates the obtaining of a carrier with an increased degree of heterogeneity.

The yield of encapsulation of a drug carrier is an important characteristic. The amount of loaded drug 


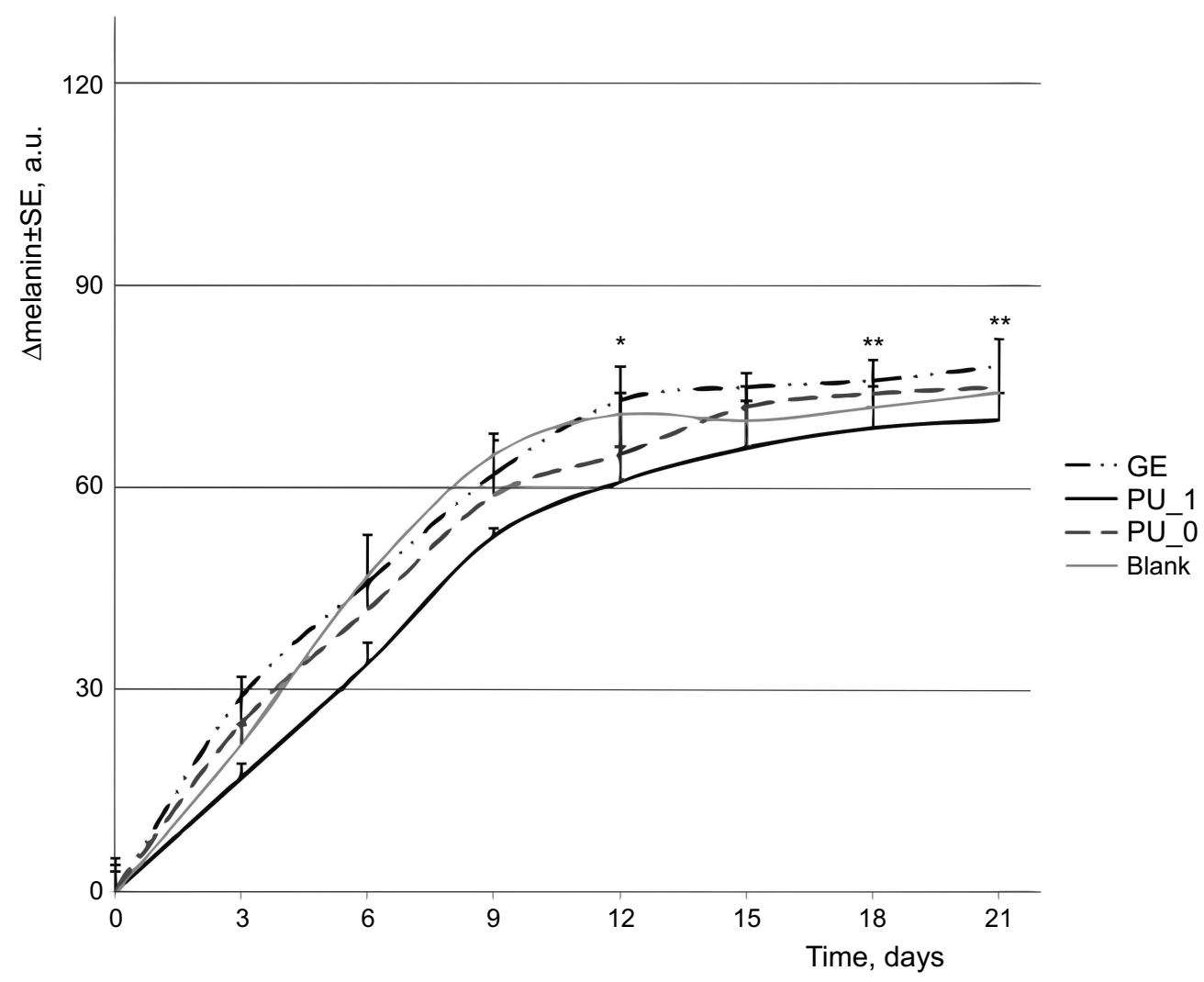

Figure 7 Evolution of melanin during the experiment.

Note: $* P<0.05$ and $* * P<0.01$ vs control.

Abbreviations: PU_0, polyurethane sample without ginger extract; PU_I, polyurethane sample with ginger extract; GE, pure ginger extract.

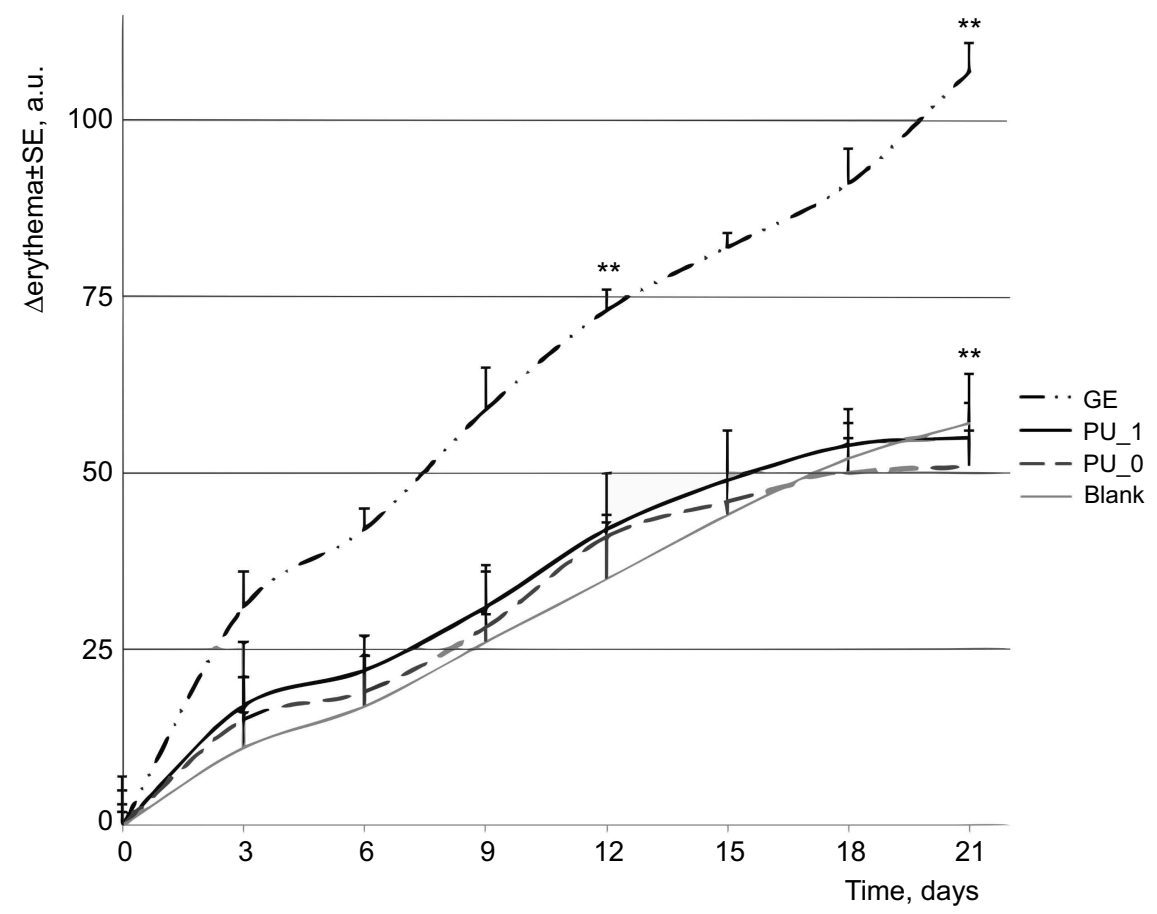

Figure 8 Evolution of erythema during the experiment.

Note: $* * P<0.01$ vs control.

Abbreviations: PU_0, polyurethane sample without ginger extract; PU_I, polyurethane sample with ginger extract; GE, pure ginger extract. 
depends on the size of carrier particles. On the other hand, Biswal et al studied the influence of drug/polymer ratio on the encapsulation efficiency. ${ }^{41}$ They found that $1: 1$ and $1: 2$ ratios lead to medium encapsulation efficiencies (between 54\% and 68\%), while 1:5 and 1:6 ratios lead to the best encapsulation efficiency (around 95\%). Hallow PU nanoparticles always present higher encapsulation efficiency than other polymer carriers such as dendrimers; we obtained satisfactory encapsulation efficiency equal with $82.9 \%$ in this research.

The evaluations of TWL and erythema show the nonirritation effects of GE samples entrapped inside PU nanoparticles.

\section{Conclusion}

In this experiment, PU nanoparticles with GE were obtained using a polyaddition process combined with a simultaneous emulsification. The products present an almost neutral $\mathrm{pH}$ and low solubility and are stable against thermal degradation. The transmembrane carrier contains particles with sizes around $90 \mathrm{~nm}$, with a medium stability against the tendency to form clusters; they absorb at 300-310 nm. Good encapsulation efficacy (82.9\%) and transmembrane penetration rate were obtained. The carrier with and without GE did not present irritation effects in in vivo testing on murine skin.

\section{Acknowledgments}

MALDI-TOF analysis was done in the Center of Genomic Medicine of "Victor Babes" University of Medicine and Pharmacy, Timisoara, Romania (POSCCE [Programul Operational Sectorial Cresterea Competitivitatii Economice (Sectoral Operational Program for the Increasing of Economic Competitiveness) Project ID: 1854, code SMIS [Sistemul Unic de Management al Informaţiei pentru Instrumentele Structurale (Unique Information Management System for Structural Instruments): 48749, "Center of Genomic Medicine v2", contract 677/09.04.2015).

\section{Disclosure}

The authors report no conflicts of interest in this work.

\section{References}

1. Mendis S, Puska P, Norrving B. Global Atlas on Cardiovascular Disease Prevention and Control. Geneva: World Health Organization; 2011.

2. Buttar HS, Li T, Ravi N. Prevention of cardiovascular diseases: role of exercise, dietary interventions, obesity and smoking cessation. Experim Clin Cardiol. 2005;10:229-249.
3. Petrovska BB. Historical review of medicinal plants' usage. Pharmacogn Rev. 2012;6:1-5. doi:10.4103/0973-7847.95849.

4. Bidlack WR, Omaye ST, Meskin MS, Topham DKW. Phytochemicals as Bioactive Agents. Boca Raton, FL: CRC Press; 2000.

5. Vasanthi HR, ShriShriMal N, Das DK. Phytochemicals from plants to combat cardiovascular disease. Curr Med Chem. 2012;19:2242-2251.

6. Gama NV, Ferreira A, Barros-Timmons A. Polyurethane foams: past, present, and future. Materials. 2018;11:E1841. doi:10.3390/ma11081451.

7. Hong K, Park S. Preparation of polyurethane microcapsules with different soft segments and their characteristics. React Funct Polym. 1999;42:193-200. doi:10.1016/S1381-5148(98)00068-6.

8. Citu IM, Toma C, Trandafirescu C, et al. Preparation and characterization of a polyurethane nanocarrier used for mixtures of betulin and fatty acids. Rev Chim Bucharest. 2015;66:431-437.

9. Oprean C, Borcan F, Pavel I, et al. In vivo biological evaluation of polyurethane nanostructures with ursolic and oleanolic acids on chemically-induced skin carcinogenesis. In Vivo. 2016;30:633-638.

10. Munteanu MF, Ardelean A, Borcan F, et al. Mistletoe and garlic extracts as polyurethane carriers - a possible remedy for choroidal melanoma. Curr Drug Deliv. 2017;14:1178-1188. doi:10.2174/ 1567201814666170126113231.

11. Borcan LC, Dudas Z, Len A, et al. Synthesis and characterization of a polyurethane carrier used for a prolonged transmembrane transfer of a chili pepper extract. Int J Nanomed. 2018;13:7155-7166. doi:10.2147/IJN.S177627.

12. Borcan F, Preda M, Borcan LC, et al. Comparative characterization of birch bark extracts encapsulated inside polyurethane microstructures. Mater Plast. 2018;55:385-388.

13. ASTM designation: D $3132-84$ (Reapproved 1996). Available from: http://reference.globalspec.com/standard/3823492/astm-d3132-841996. Accessed October 24, 2018.

14. Bouchemal K, Briançon S, Bonnet I, et al. Synthesis and characterization of polyurethane and poly(ether urethane) nanocapsules using a new technique of interfacial polycondensation combined to spontaneous emulsification. Int J Pharm. 2004;269:89-100. doi:10.1016/j. ijpharm.2003.09.025.

15. Amanda reasoner: teaching osmosis and diffusion through kidney dialysis. Available from: http://teachersinstitute.yale.edu/nationalcurri culum/units/2011/7/11.07.07.x.html. Accessed December 11, 2018.

16. Rogiers V; EEMCO Group. EEMCO guidance for the assessment of transepidermal water loss in cosmetic sciences. Skin Pharmacol Appl Skin Physiol. 2001;14:117-128. doi:10.1159/000056341.

17. Proksch E, Brandner JM, Jensen JM. The skin: an indispensable barrier. Exp Dermatol. 2008;17:1063-1072. doi:10.1111/j.16000625.2008.00786.x.

18. Heghes A, Soica CM, Ardelean S, et al. Influence of emulsifiers on the characteristics of polyurethane structures used as drug carrier. Chem Cent J. 2013;7:66. doi:10.1186/1752-153X-7-66

19. MPA5-MX18 manual. Available from: https://www.courage-khazaka.de/ en/scientific-products/all-products/probe-systems. Accessed December 11, 2018.

20. Ketata N, Sanglar C, Waton H, et al. Thermal degradation of polyurethane bicomponent systems in controlled atmospheres. Polym Polym Compos. 2005;13:1-26. doi:10.1177/096739110501300101.

21. O'Neill MJ. The analysis of a temperature-controlled scanning calorimeter. Anal Chem. 1964;36:1238-1245. doi:10.1021/ ac60213a020.

22. Bolcu C, Borcan F, Nutiu R. Aspects regarding the synthesis and characterization of some types of thermoplastic polyurethanes. Mater Plast. 2006;43:258-261.

23. Murthy SK. Nanoparticles in modern medicine: state of the art and future challenges. Int J Nanomed. 2007;2:129-141.

24. Majewski M, Carneiro C, Ibler E, et al. Digital dermoscopy to determine skin melanin index as an objective indicator of skin pigmentation. J Surg Dermatol. 2016;1:37-42. doi:10.18282/jsd.v1.i1.15 
25. Boon WPC. Demanding Dynamics - Demand Articulation of Intermediary Organisations in Emerging Pharmaceutical Innovations [Dissertation]. Utrecht University Repository; 2008.

26. Jerome C, Lecomte P. Recent advances in the synthesis of aliphatic polyesters by ring-opening polymerization. Adv Drug Deliv Rev. 2008;60:1056-1076. doi:10.1016/j.addr.2008.02.008

27. Dhanik J, Arya N, Nand V. A review on Zingiber officinale. J Pharm Phytochem. 2017;6:174-184.

28. Shirooye P, Mokaberinejad R, Ara L, et al. Volatile constituents of ginger oil prepared according to iranian traditional medicine and conventional method: a comparative study. Afr $J$ Tradit Complement Altern Med. 2016;13:68-73. doi:10.21010/ajtcam. v13i6.11.

29. Verma SK, Singh M, Jain P, et al. Protective effect of ginger, Zingiber officinale Rosc on experimental atherosclerosis in rabbits. Indian J Exp Biol. 2004;42:736-738.

30. Young H, Liao J, Chang Y, et al. Synergistic effect of ginger and nifedipine on human platelet aggregation: a study in hypertensive patients and normal volunteers. Am J Chin Med. 2006;34:545-551. doi:10.1142/S0192415X06004089.

31. Bordia A, Verma S, Srivastava K. Effect of ginger (Zingiber officinale Rosc.) and fenugreek (Trigonella foenumgraecum L.) on blood lipids, blood sugar and platelet aggregation in patients with coronary artery disease. Prostaglandins Leukot Essent Fatty Acids. 1997;56:379-384. doi:10.1016/S0952-3278(97)90587-1.

32. Ali B, Blunden G, Tanira M, Nemmar A. Some phytochemical, pharmacological and toxicological properties of ginger (Zingiber officinale Roscoe): a review of recent research. Food Chem Toxicol. 2008;46:409-420. doi:10.1016/j.fct.2007.09.085.
33. Afzal M, Al-Hadidi D, Menon M, et al. Ginger: an ethnomedical, chemical and pharmacological review. Drug Metab Drug Interact. 2001;18:159-190. doi:10.1515/DMDI.2001.18.3-4.159.

34. Ghayur M, Gilani A, Afridt M, et al. Cardiovascular effects of ginger aqueous extract and its phenolic constituents are mediated through multiple pathways. Vascul Pharmacol. 2005;43:234-241. doi:10.1016/j.vph.2005.07.003.

35. Al-Amin Z, Thomson M, al-Qattan K, et al. Anti-diabetic and hypolipidaemic properties of ginger (Zingiber officinale) in streptozotocin-induced diabetic rats. Br J Nutr. 2006;96:660-666. doi:10.1079/BJN20061849.

36. Bhandari U, Kanojia R, Pillai K. Effect of ethanolic extract of Zingiber officinale on dyslipidemia in diabetic rats. $J$ Ethnopharmacol. 2005;97:227-230. doi:10.1016/j.jep.2004.11.011.

37. Akhani S, Vishwakarma S, Goyal R. Antidiabetic activity of Zingiber officinale in streptozotocin-induced type 1 diabetic rats. J Pharm Pharmacol. 2004;56:101-105. doi:10.1211/0022357022403.

38. Roufogalis BD. Zingiber officinale (Ginger): a future outlook on its potential in prevention and treatment of diabetes and prediabetic states. New J Sci. 2014;2014:674-684. doi:10.1155/2014/674684.

39. Stepto RFT, Gilbert RG, Hess M, et al. Dispersity in polymer science. Pure Appl Chem. 2009;81:351-353. doi:10.1351/PAC-REC-08-0502.

40. Ketata N, Sanglar C, Waton H, et al. Synthesis, mechanisms and kinetics of formation of bi-component polyurethanes. Polym Polym Compos. 2004;12:645-665. doi:10.1177/096739110401200801.

41. Biswal I, Dinda A, Mohanty S, et al. Influence of drug/polymer ratio on the encapsulation efficiency of highly hydrophilic drug. Asian J Chem. 2011;23:1973-1978.

\section{Publish your work in this journal}

The International Journal of Nanomedicine is an international, peerreviewed journal focusing on the application of nanotechnology in diagnostics, therapeutics, and drug delivery systems throughout the biomedical field. This journal is indexed on PubMed Central, MedLine, CAS, SciSearch ${ }^{\text {, }}$ Current Contents /Clinical Medicine,
Journal Citation Reports/Science Edition, EMBase, Scopus and the Elsevier Bibliographic databases. The manuscript management system is completely online and includes a very quick and fair peer-review system, which is all easy to use. Visit http://www.dovepress.com/ testimonials.php to read real quotes from published authors. 